\section{Cerebral pial arteriovenous fistula with associated varix treated by direct surgery}

\author{
Sir,
}

Cerebral pial arteriovenous fistula (AVF), fistula between the pial or cortical arteries and a draining vein without an intervening vascular network is a rare vascular malformation..$^{[1]}$ The optimum treatment strategy is uncertain. Various treatment options include: Direct surgery, endovascular treatment or both. ${ }^{[1-5]}$ Several recent reports have used endovascular techniques to treat AVF successfully. ${ }^{[6-8]}$ We focus on the merits of direct surgical treatment of AVF in an easily accessible location.

A 14-year-old male presented with right focal onset convulsive seizures. Neurological examination was essentially normal. T2-weighted magnetic resonance (MR) images demonstrated a signal flow void lesion in the left parietal convexity, around which tortuous hypointensity was seen, suggesting an enlarged feeding artery and a draining vein [Figure 1]. A left internal carotid angiogram revealed an AVF between an enlarged angular artery and an associated varix in the ascending parietal vein with marked ectasia that drained into the superior sagittal sinus [Figure 2].

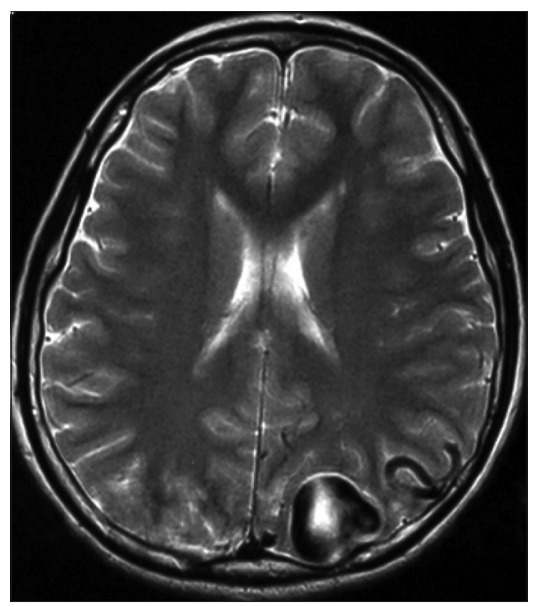

Figure 1: Axial T2-weighted MR image demonstrating a heterogeneous flow void lesion
Patient underwent a left-sided parieto-occipital craniotomy in the prone position. A craniotomy was extended to the opposite side across the superior sagittal sinus. Following the dural incision, we found a cerebral pial AVF between an enlarged angular artery and an associated varix on the parietal cortex. Around the fistulous communication site, the enlarged angular artery and associated varix were carefully dissected from the surrounding brain tissue. We also found small branches arising from the enlarged angular artery near the fistula [Figure 3]. Branches draining into the fistula site near the varix were cauterized and those draining into normal brain tissue were preserved by careful dissection. The varix collapsed and lost turgidity immediately after clipping the angular artery near to the fistula site. Next, we interrupted a draining vein that was found running towards the superior sagittal sinus and the varix wall was excised without any intraoperative active bleeding. Careful inspection revealed a single pore of an excurrent draining vein inside the varix and disconnection of the fistula was completed by permanent clipping. We did not peel off the varix wall from the adjacent cerebral parenchyma any further, as the varix was adherent firmly to the surrounding brain parenchyma. Postoperative cerebral angiography confirmed complete disappearance of the AVF as well as the associated varix. The distal part of the angular artery remained dilated, but demonstrated normal venous drainage [Figure 4]. The patient returned to normal school life without any neurological deficits and was free from seizures at a two-year followup examination.

Pial AVFs are rare vascular malformations that have abnormal direct connections between feeding arteries and a draining vein without intervening vascular networks, and have been recently recognized as a distinct entity, different from arteriovenous malformations (AVMs) and dural AVFs. They can be fed

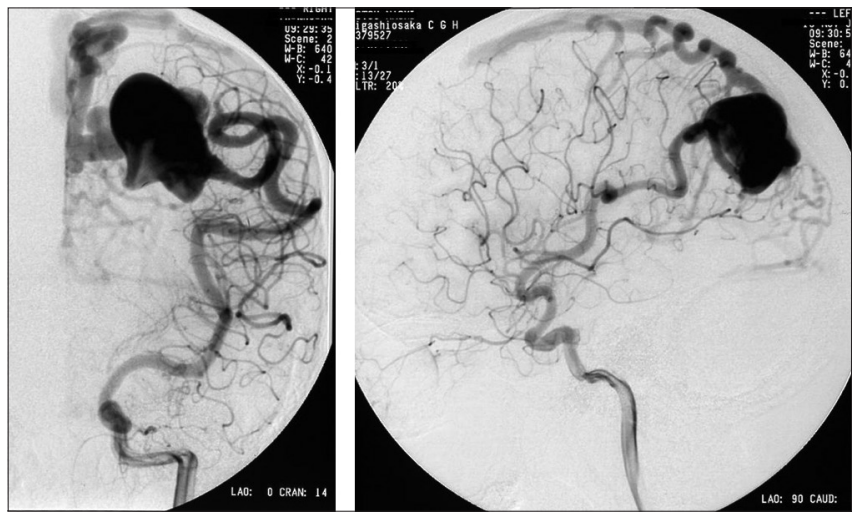

Figure 2: Left internal carotid angiograms (Left: Anteroposterior view, Right: Lateral view) revealing a direct AVF between an enlarged angular artery and associated varix on the ascending parietal vein draining into the superior sagittal sinus. The ascending parietal vein demonstrates marked ectasia 


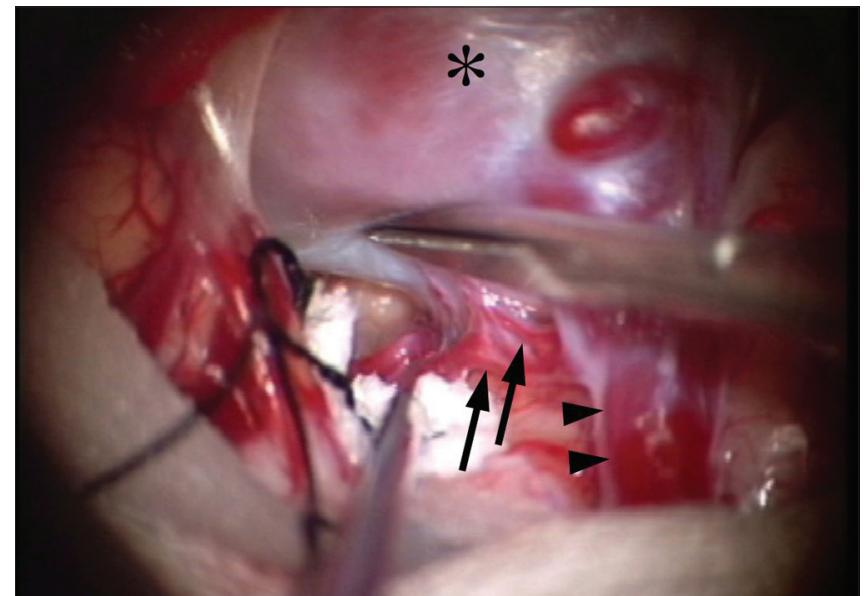

Figure 3: Intraoperative findings. Shown is an AVF with a direct connection between an enlarged angular artery (arrowheads) and associated varix (asterisk). Small branches can be seen arising from the enlarged angular artery near the fistula (arrows)

by one or more feeding arteries from the pial or cortical arteries, and can be supratentorial (cerebral pial AVFs) or infratentorial (cerebellar pial AVFs) in location. The exact pathogenesis and the natural history of pial AVFs have not been well elucidated. The reported frequency varies between $0.3 \%$ (13 of $500 \mathrm{AVMs})^{[7]}$ and $4.8 \%$ (12 of 251 AVMs). ${ }^{[1]}$ A notable feature of cerebral pial AVFs is their high-flow nature and they are often associated with a large varix ${ }^{[1,3-7]}$ The reported clinical features include: Obstructive hydrocephalus, developmental delay, enlarged head circumference, cranial bruit, cardiac failure, hemorrhage, and seizures. ${ }^{[3,5-7]}$ Cardiac failure is an important characteristic clinical feature in neonates, ${ }^{[6,7]}$ while headaches, neurological deficits, and hemorrhage are the clinical manifestations in adulthood..$^{[1,2,4,8,9]}$

The treatment goal for pial AVFs is disconnection of the fistula from its vascular supply either by surgery, endovascular procedure, or both. ${ }^{[2,3,10]}$ Clipping or embolization of the feeders without lesion resection has been recommended by Hoh et al. ${ }^{[2]}$ In this patient, we decided to perform direct surgical disconnection of the fistula as the lesion was located in an easily accessible location in the parietal convex and involved a simple vascular complex. Direct visualization using a microsurgical technique enabled confirmation of the small branches connecting the fistula, which otherwise could not have been detected by angiography. It is important to recognize that a pial AVF may involve multiple feeders which can result in recurrence if left unattended while treating these AVFs. ${ }^{[10]}$ Our opinion is that direct surgery, performed when appropriate, enables recognition of occult feeding arteries and confirmation of complete obliteration of the fistula under direct visualization. Further, arterial branches

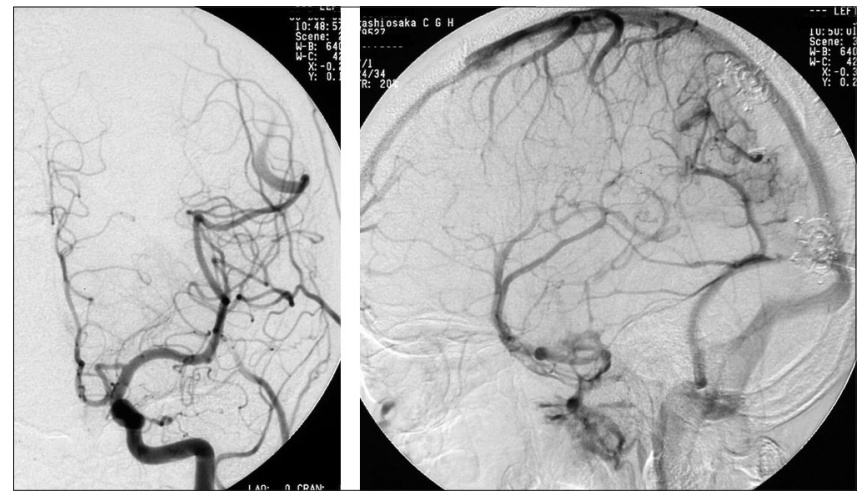

Figure 4: Postoperative left common carotid angiograms (Left: Anteroposterior view; arterial phase, Right: Lateral view; venous phase) demonstrating disappearance of the AVF and associated varix. The distal part of the angular artery remains dilated, but demonstrates normal venous drainage

arising near the fistula that go to normal brain tissue should be preserved to prevent neurological deficits. The merits of a direct operation were emphasized in a recent report. ${ }^{[9]}$ While endovascular techniques are increasingly gaining importance, direct surgery can still be an option for pial AVFs located in an easily accessible location.

\section{Hiroshi Yokota, Kazuhiro Yokoyama, Yoshitomo Uchiyama, Seiji Kinoshita}

Departments of Neurosurgery and ${ }^{1}$ Pediatrics, Higashiosaka City General Hospital, Osaka, Japan. E-mail: h-yokota@higashiosaka-hosp.jp

DOI: $10.4103 / 0028-3886.59493$

\section{References}

1. Tomlinson FH, Rufenacht DA, Sundt TM Jr, Nichols DA, Fode NC. Arteriovenous fistulas of the brain and the spinal cord. J Neurosurg 1993;79:16-27.

2. Hoh BL, Putman CM, Budzik RF, Ogilvy CS. Surgical and endovascular flow disconnection of intracranial pial single-channel arteriovenous fistulae. Neurosurgery 2001;49:1351-64.

3. Barnwell SL, Ciricillo SF, Halbach VV, Edwards MS, Cogen PH. Intracerebral arteriovenous fistulas associated with intraparenchymal varix in childhood: Case reports. Neurosurgery 1990;26:122-5.

4. Giller CA, Batjer HH, Purdy P, Walker B, Mathews D. Interdisciplinary evaluation of cerebral hemodynamics in the treatment of arteriovenous fistulae associated with giant varices. Neurosurgery 1994; 35:778-84

5. Pillai A, Rajeev K, Unnikrishnan M. Surgical management of a pial arteriovenous fistula with giant varix in an infant. Neurol India 2006;54:434-6.

6. Weon YC, Yoshida Y, Sachet M, Mahadevan J, Alvarez H, Rodesch G, et al. Supratentorial cerebral arteriovenous fistulas (AVFs) in children: Review of 41 cases with 63.non choroidal single-hole AVFs. Acta Neurochir (Wien) 2005;147:17-31.

7. Nelson K, Nimi Y, Lasjaunias P, Berenstein A. Endovascular embolization of congenital intracranial pial arteriovenous fistulas. Neuroimaging Clin N Am 1992;2:309-17.

8. Limaye US, Siddhartha W, Shrivastav M, Anand S, Ghatge S Endovascular management of intracranial pial arterio-venous fistulas. 
Neurol India 2004;52:87-90.

9. Passacantilli E, Pichierri A, Guidetti G, Santoro A, Delfini R. Surgical treatment of pial cerebellar arteriovenous fistulas with aneurysm of the main feeding artery. Surg Neurol 2006;65:90-4.

10. Tawk RG, Bendok BR, Ali MJ, Getch CC, Batjer HH. Surgical treatment of cerebral arteriovenous fistulas in children. In: Alexander MJ, Spetzler RF, editors. Pediatric neurovascular disease: Surgical, endovascular, and medical management. New York: Thieme Medical Publishers; 2006. p. 90-103.

Accepted on 03-02-2009 